\title{
Entre "saber y no saber tomar": representaciones y prácticas de varones y mujeres sobre el consumo de alcohol en Yucatán
}

\author{
Between "knowing and not knowing how to handle \\ alcohol:" Social representations and practices of men \\ and women regarding alcohol consumption in Yucatán
}

${ }^{1}$ Doctor en Antropología. Centro de Investigaciones y Estudios Superiores en Antropología Social, Ciudad de México, México. $\triangle$ iD
RESUMEN Este trabajo da cuenta de las representaciones y prácticas sociales de varones y mujeres de un municipio de Yucatán, respecto de la negatividad, positividad y ambivalencia del consumo de alcohol en su salud y relaciones sociales (violentas y no violentas), partiendo de las categorías locales del "saber tomar" y el "no saber tomar". La etnografía se desarrolló desde un abordaje de la antropología médica crítica y del enfoque relacional. El trabajo de campo se llevó a cabo durante 11 meses (2016-2017), en Cuzamá, municipio en la zona ex-henequenera de Yucatán (México), tiempo en el que el investigador vivió y convivió en la comunidad. Se trabajó con ocho actores significativos (cuatro varones y cuatro mujeres de 25 a 40 años de edad) y otros secundarios y terciarios, a través de entrevistas individuales, algunas grupales, conversaciones "informales" $\mathrm{y}$, sobre todo, de la observación participante. Los resultados muestran que, a nivel de representaciones, el consumo se enuncia predominantemente desde su negatividad y, si bien se corresponde e incluso se identifica con ciertas afectaciones para la salud, a nivel de las prácticas, el consumo deriva en beneficios para la salud física, emocional y relacional, evidenciándose que los saberes sociales de las personas sobre el consumo de alcohol se caracterizan más por sus discontinuidades y ambivalencias que por sus continuidades.

PALABRAS CLAVES Antropología Médica; Consumo de Bebidas Alcohólicas; México.

\begin{abstract}
This study presents an account of social representations and practices of men and women in a Yucatán municipality regarding the negativity, positivity, and ambivalence over alcohol consumption with respect to their health and social relationships (violent and non-violent), based on the local categories of "knowing how to handle alcohol" and "not knowing how to handle alcohol." This ethnography was conducted within the framework of critical medical anthropology with a relational approach. Fieldwork was carried out over a period of 11 months (2016-2017) in Cuzamá, a municipality in the former henequen-producing area of Yucatán. During this period, the researcher resided in and lived alongside the community. The research was primarily conducted with eight significant actors (four men and four women from 25 to 40 years old), as well as other secondary and tertiary actors, through individual interviews, group interviews, "informal" conversations, and above all participant observation. The results show that in terms of representations, alcohol consumption is primarily discussed from a place of negativity. Although it leads to and is in fact associated with certain health problems, in terms of practices, alcohol consumption is seen as the source of physical, emotional, and relational health benefits. This is evidenced in popular knowledge regarding alcohol consumption, which is characterized by discontinuity and ambivalence more than continuity.
\end{abstract}

KEY WORDS Medical Anthropology; Alcohol Drinking; Mexico. 


\section{INTRODUCCIÓN}

El reporte más reciente de la Organización Mundial de la Salud ${ }^{(1)}$ indica que, en 2016, el consumo de alcohol causó el 5,3\% del total de las defunciones mundiales, fue responsable de al menos el $5 \%$ de la carga mundial de lesiones y de morbilidad, y se estimó que casi el $3 \%$ de la población global presenta un trastorno por abuso o dependencia al alcohol. En contraste, poco más de la mitad (53\%) de la población mundial de 15 años o más se reconocen bebedores actuales -bebieron al menos en una ocasión en los últimos 12 meses-, y casi una quinta parte (18\%) admite un episodio de alto consumo de alcohol en el último año, es decir, que bebió más de 60 gramos de alcohol puro por ocasión $-1,7$ litros de cerveza, poco más de cuatro copas de vino tinto o cinco cocteles-, lo que derivaría en una intoxicación aguda por alcohol.

En México, y de acuerdo a la última Encuesta Nacional de Consumo de Drogas, Alcohol y Tabaco realizada entre 2016 y $2017^{(2)}$, el $71 \%$ de las personas encuestadas admitió ser consumidoras actuales. Al comparar estos datos con mediciones previas ${ }^{(3)}$, el consumo diario se reportó como "muy poco frecuente" aunque pasó del 0,8\% al 2,9\% de 2011 a 2016 y, aunque la dependencia disminuyó del 5,5\% al 2,2\%, el consumo de "altas cantidades por ocasión" aumentó del 4,3\% al $8,3 \%$ en los mismos años, siendo el patrón de consumo más reportado en el último mes y que representa la principal forma de beber de al menos el $40 \%$ de la población adulta bebedora de México(1), en su mayoría, varones.

A nivel local, la última Encuesta Estatal de Adicciones de Yucatán, realizada entre 2014 y $2015^{(4)}$, indicó que el $46 \%$ de la población encuestada admitió consumir alcohol en el último año -aparentemente menos que a nivel nacional-, y aunque solo el $8,1 \%$ reportó criterios de dependencia, esta cifra contrasta por su aumento respecto del 3,3\% reportado en $2005^{(5)}$. Pero, además, y en discrepancia con la "baja" dependencia alcohólica, la intoxicación aguda por alcohol -beber en una sola ocasión más de 60 gramos de alcohol puro hasta intoxicarse- ha posicionado a Yucatán en los primeros lugares a nivel nacional, desde 2005 en el caso de los varones y 2013 en el caso de las mujeres, registrándose 7.905 varones intoxicados y 1.146 mujeres en $2017^{(6)}$.

Es importante decir que, a pesar de que las mediciones de estos reportes y encuestas a nivel global, nacional y local difieren en términos metodológicos, técnicos e incluso conceptuales y no son metodológicamente comparables, sus datos ofrecen un útil panorama sobre los patrones de consumo de las personas y los conjuntos sociales. En ellos se destaca que mientras la dependencia y la frecuencia de consumo parecen no ser muy altas en términos porcentuales -particularmente, para el caso mexicano y yucateco-, los episodios de alto consumo y los casos de intoxicación aguda por alcohol van en aumento. Esto indica que, mientras los sujetos dicen no beber mucho y no tener problemas de dependencia, cuando de hecho beben, lo hacen en altas cantidades y hasta intoxicarse, lo que deriva en importantes consecuencias negativas para la salud en términos crónicos y agudos.

Por ejemplo, para 2017, entre las primeras diez causas de mortalidad de la población yucateca en general ${ }^{(7)}$, tres se relacionaron de forma directa ("enfermedad alcohólica del hígado" o cirrosis) y de forma indirecta con el consumo de alcohol ("accidentes en vehículos de motor" y por "lesiones autoinfligidas intencionalmente" o suicidios). Los accidentes y los suicidios ocuparon, ese mismo año, el primero y el segundo lugar de las causas de mortalidad entre varones de 15 a 34 años de edad, mientras que en el grupo de 35 a 44 años estas posiciones fueron para los accidentes y la enfermedad alcohólica del hígado (cirrosis); en cambio, entre los 45 y los 64 años de edad, la cirrosis alcohólica se posicionó por encima de todas las demás causas vinculadas directa o indirectamente al consumo de alcohol. En el caso de las mujeres yucatecas de 15 a 24 años y para el mismo año, los accidentes aparecieron en quinto lugar, mientras que los suicidios se posicionaron en segundo, ocupando también esta posición para el grupo de los 25 a los 34 años; mientras que las muertes femeninas por 
cirrosis alcohólica no figuran en la lista de las primeras veinte causas de mortalidad, hasta los 35 años de edad.

Lo anterior muestra que, en términos inmediatos y agudos, los accidentes, suicidios e intoxicaciones confirman la negatividad del consumo de alcohol en la salud pública de Yucatán, especialmente, en personas jóvenes y en varones adultos, mientras que la cirrosis hepática alcohólica corrobora la prevalencia de padecimientos crónicos que van escalando con el paso del tiempo, más en los varones, pero en ascenso en las mujeres. Además, las encuestas señaladas y otros trabajos ${ }^{(8,9)}$ han indicado que, al menos una parte de la población, conoce de estas consecuencias, sin por ello reducir, interrumpir o suspender la ingesta, ante lo cual surgen las siguientes preguntas: ¿todo consumo de alcohol se vive como negativo? ¿Es siempre un problema de salud para la población, o para quiénes y en qué circunstancias? ¿Cómo determinan los sujetos sociales su negatividad y/o positividad?

Este artículo trata sobre las representaciones y prácticas sociales de varones y mujeres sobre el consumo de alcohol y sus variadas consecuencias en la salud y las relaciones sociales de varones y mujeres de un municipio de Yucatán.

\section{NOTAS METODOLÓGICAS}

Este texto se desprende de una tesis doctoral ${ }^{(10)}$ desarrollada desde la antropología médica crítica ${ }^{(11)}$ y con un enfoque relacional ${ }^{(12)}$, en la que se plantearon tres problemas de investigación que, en conjunto, refieren a los saberes (representaciones y prácticas sociales) de varones y mujeres sobre el consumo de alcohol y sus consecuencias en la salud, recursos económicos y relaciones sociales cotidianas. En este artículo, retomo parte de los resultados del primer problema de investigación sobre la negatividad y la positividad y, sobre todo, la ambivalencia de las consecuencias de este consumo, organizándolo en dos apartados: a) la configuración social y ambivalencia de estos saberes, y b) cómo esa ambivalencia se expresa en el proceso de salud/enfermedad/atención-prevención.

El trabajo de campo fue desarrollado durante once meses entre 2016 y 2017, en Cuzamá, municipio céntrico del estado de Yucatán (México) a 48 kilómetros de la ciudad capital (Mérida), ubicado en la ex-zona henequenera y que hoy forma parte del Ilamado "Anillo de los cenotes". Si bien no existen datos epidemiológicos que caractericen a Cuzamá como un municipio emblemático respecto al consumo de alcohol y a sus consecuencias, mis registros y experiencia de trabajo previo en la zona como psicólogo social-comunitario (de 2011 a 2013) muestran un continuo señalamiento y preocupación por parte de la población respecto del elevado "alcoholismo" en la comunidad ${ }^{(13,14)}$, por lo que su elección corresponde tanto a los saberes locales como a un compromiso personal con este municipio.

Los métodos de investigación utilizados fueron entrevistas individuales, algunas entrevistas grupales, conversaciones "informales", conversaciones "terapéuticas" -solicitadas por algunas personas debido a mi formación psicológica y terapéutica y descritas en la te$\operatorname{sis}^{(10)}-y$, sobre todo, la observación participante. Hay que resaltar que, aunque dentro del diseño metodológico no fue requisito la evaluación del proyecto por parte de un Comité Ético de Investigación, sí se llevaron a cabo acciones para informar a la población y a las y los actores sociales sobre el tópico y naturaleza del estudio: a) una carta de presentación en la que se planteaban los motivos y tiempos de la investigación, que fue entregada (y sellada de recibido) a la Presidencia Municipal, a las y los directores de las distintas escuelas del municipio, al centro de salud local y a algunos líderes religiosos; b) carteles de presentación distribuidos en zonas públicas y visibles de la comunidad por medio de los cuales anuncié la intención y temporalidad de mi estancia; c) y cartas de consentimiento informado previamente explicadas y firmadas en cada entrevista individual y grupal, enterando así a cada actor de la intención del estudio y de la confidencialidad de la información recabada, respetando en todo momento su deseo de participar o de no 
continuar, asegurándoles que sus datos personales serían modificados.

Los actores sociales significativos con quienes trabajé fueron ocho personas (cuatro varones y cuatro mujeres) consumidoras de alcohol de entre 25 y 40 años de edad, originarias y residentes de Cuzamá, de estados civiles e ingresos variados, aunque con un nivel educativo relativamente similar (secundaria o bachillerato finalizado), y con un mismo acceso a servicios básicos de electricidad, agua potable y drenaje sanitario. También trabajé con actores secundarios y terciarios, esto es, con personas vinculadas directamente a los actores primarios (padres, madres, esposas, amigas y amigos) y con representantes de diferentes instituciones locales (salud, educación, religión, gobierno, etc.). Es importante señalar que a lo largo de este artículo utilizo la palabra varón-varones como referentes sexuales, y la de hombre-hombres como referentes de género, para diferenciar el hecho biológico del hecho y proceso sociocultural (masculinidad), razón por la cual varón/varones no referirán a nociones como varonil, viril, virilidad o similares.

Por actores sociales me refiero a: 1) sujetos que no solo informan lo que creen y opinan (representaciones) sobre un problema, sino que también lo actúan y viven (prácticas), razón por la cual la observación participante fue central; 2) personas que aunque ejercen su subjetividad, no se representan exclusivamente a sí mismos como individuos sino que representan al "varón" y a la "mujer" en tanto sujetos sociales inmersos en relaciones sociales; 3) y, desde este enfoque, parto del supuesto de que siempre hay más de un actor social en un problema de investigación -en este caso, varones y mujeres-, y que es en sus relaciones donde se accede y comprenden sus saberes sociales.

Por último, la noción de saber(es) social(es) es tomada de la propuesta del enfoque relacional ${ }^{(10,12)}$ y refiere a las representaciones y prácticas sociales de los sujetos, es decir, a lo que dicen y piensan pero también a lo que hacen en su vida y relaciones cotidianas (se distingue en este texto de las categorías "saber tomar" y "no saber tomar", usando cursivas para la primera y "comillas" para las segundas). Los saberes sociales no son siempre continuos, congruentes ni homogéneos entre sí, como tampoco lo son al interior de las propias representaciones o prácticas; se caracterizan por su heterogeneidad al interior de un mismo grupo social o entre sí, y también por sus contradicciones y ambivalencias. Esto es crucial si lo que se busca -como es el caso de este esfuerzo- es el estudio crítico y contemporáneo del consumo de alcohol, que evite descripciones polarizadas que den cuenta solo de la funcionalidad positiva del consumo o de su negatividad.

Como nota aparte, considero que la propuesta teórica de los saberes sociales - utilizada en mi caso desde la antropología médica- no es opuesta a lo planteado por las teorías del "pensamiento social cotidiano" y de las "representaciones sociales" de la psicología social. Más aún, Wagner y Hayes ${ }^{(15)}$ señalan que el mismo Moscovici definió las representaciones sociales como sistemas de valores, de ideas y también de prácticas, pero que estas últimas habían sido -y suelen ser- desatendidas en la investigación de la relación sujeto-objetogrupo (en mi caso: actores-consumo de alcohol-relaciones sociales). Ante esto, los autores recomiendan apoyarse en la etnografía y particularmente en la observación, para abordar la complejidad de las "representaciones" (psicología social) o, en nuestro caso, de los saberes sociales (antropología médica). Esta aparente contradicción teórica, que más bien parece complementaria, quedará para otra discusión.

\section{ENTRE "SABER TOMAR" $Y$ "NO SABER TOMAR"}

\section{La configuración social (y ambivalente) del consumo de alcohol y sus consecuencias}

La antropología del alcoholismo, de importante desarrollo y producción internacional y nacional entre las décadas de 1930 y $1980^{(9,16,17)}$, dejó en claro que la forma en la que la mayoría de los conjuntos sociales beben y experimentan las consecuencias del consumo de alcohol, se caracteriza por su 
"naturaleza" sociocultural, es decir, por el papel de la cultura en los usos del alcohol y por el papel de los usos del alcohol en la cultura, lo que apunta a la necesidad de un modelo sociocultural que estudie este proceso $^{(17)}$. Esto significa que, más allá de los efectos psicotrópicos en el comportamiento de individuos particulares, la investigación de este consumo debiera remitirnos a su interrelación con los elementos históricos, políticoeconómicos, ideológicos y culturales que le subyacen, esto es, el proceso de alcoholización $^{(18)}$. Por ello, insisto, es menester una aproximación antropológica que reconozca todas las formas de consumo de la mayoría de la población pues en palabras de Horton, estas "constituyen el punto lógico de partida para la explicación básica de los problemas vinculados a la ingestión de alcohol"(19).

Los resultados de mi trabajo en Cuzamá confirman que el tipo de bebida y su presentación, la cantidad y frecuencia de consumo, su forma y dinámica de ingesta, el lugar donde se bebe, el momento del día o de la semana, cuánto dinero se gasta en ello, así como con quiénes se bebe y con quiénes no, está cargado de saberes que se configuran en el contexto y las relaciones sociales. Las categorías locales "saber tomar" y "no saber tomar" sintetizan la positividad y negatividad que los sujetos identifican en este consumo, y se expresan a través de subcategorías como "tomar dos" (invitación y obligación para el consumo colectivo), el "ambiente" (diversión y convivencia) o tomar con "la banda" (pares).

"Saber" y "no saber tomar" aparecen como las dos caras de una misma moneda cultural: se definen y significan mutuamente. Son expresiones cotidianas que representan lo "bueno" y lo "malo" del beber en términos de comportamientos, formas de interacción y obligaciones que constituyen el marco cultural explicativo desde el cual los varones y mujeres de Cuzamá determinaban si beber alcohol conllevaba a consecuencias buenas o malas (o ambas). A propósito, el uso que hago de la noción cultura y cultural se apoya en los trabajos de Menéndez ${ }^{(20)}$, en términos de rutinas y rituales cotidianos, repetitivos y habituales, que llegan a estructurar la vida social cotidiana en momentos determinados $y$, aunque no siempre seamos "conscientes" de ello, su ritualidad garantiza su reproducción.

"Saber tomar" expresaba lo deseado y esperado en el consumo, mientras que "no saber tomar" daba cuenta de lo rechazado y lo sancionado localmente -aun cuando no se confrontara ni se cambiara necesariamente la práctica de consumo. Ambas categorías se manifestaban en la oposición "tomador/borracho" y su alcance era "medido" por su impacto en la salud -física, psicológica y relacional-, en los recursos económicos -gubernamentales, privados y domésticos- y en las relaciones sociales, violentas y no violentas (Figura 1).

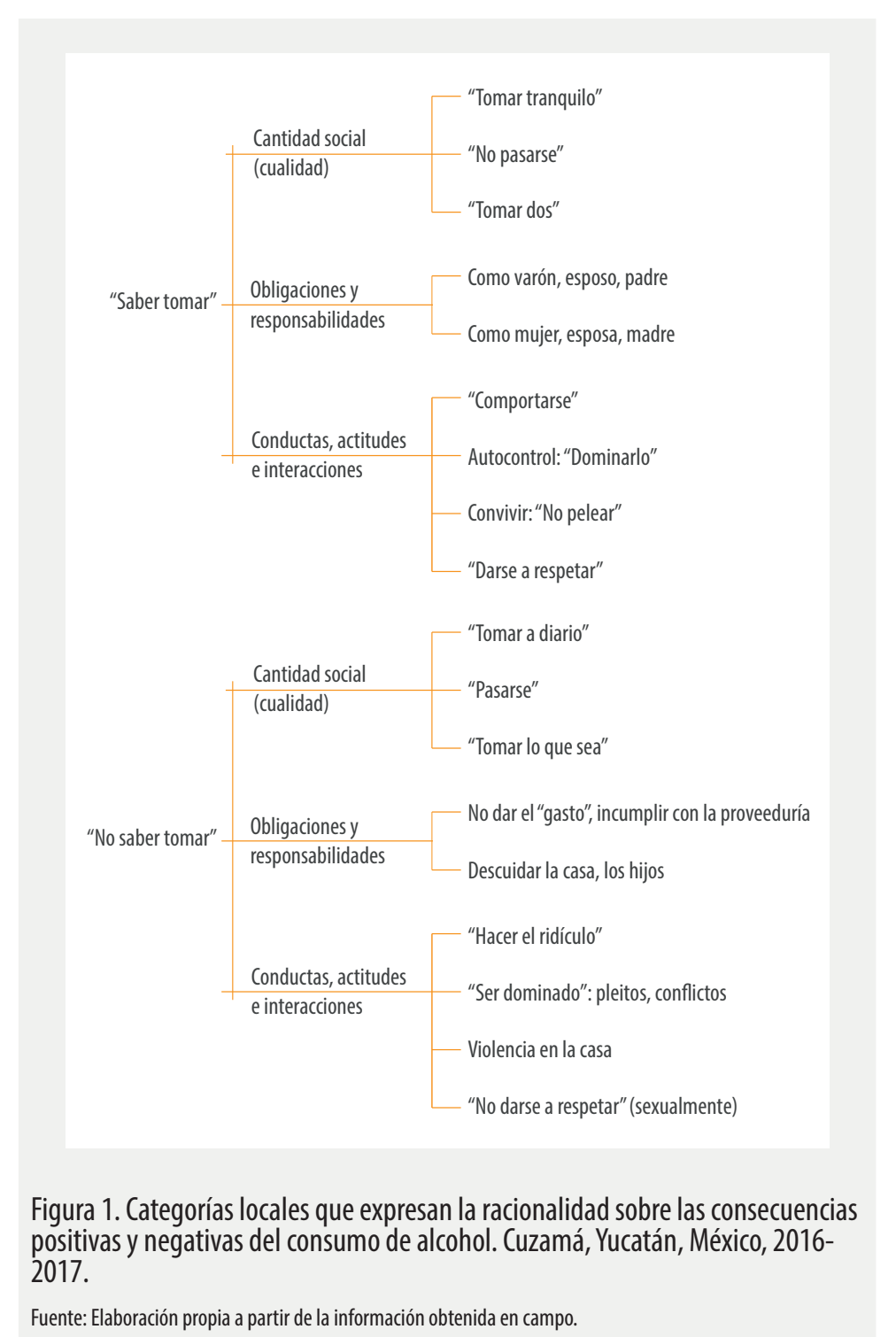

Figura 1. Categorías locales que expresan la racionalidad sobre las consecuencias positivas y negativas del consumo de alcohol. Cuzamá, Yucatán, México, 20162017.

Fuente: Elaboración propia a partir de la información obtenida en campo. 
Como se mencionó, en este texto solo se abordan las consecuencias para la salud y para las relaciones sociales por motivos de extensión, sin embargo, se hacen algunas menciones de las consecuencias económicas vinculadas al consumo de alcohol.

Aunque no hay registros de una representación local que explícitamente diera cuenta de un consenso generalizado sobre la cantidad de alcohol que se podía beber para considerar que alguien "sabe tomar" o no, la recurrencia y habitualidad de expresiones como "pasarse", "tomar sin pasarse", "tomar tranquilo" o "comportarse", revelan la existencia de una medida social para este consumo. "Pasarse" indica llegar a un punto en el que se cometen imprudencias en la interacción con otros, o se hace el ridículo, o ya no es posible caminar, sostenerse o hablar, o se bebe con más frecuencia como explica Olga (actora significativa, 34 años): "no está mal tomar una o dos cervezas... lo malo es cuando te pasas, es cuando se vuelve vicio tomar diario".

La única mención cuantitativa en este sentido remite de nuevo a la oposición "tomador/borracho", en palabras de Memo:

...acá, a los borrachos se les considera... como los alcohólicos, o sea, que diario toman, día y noche, como los que están por mi casa que a diarios están tomando. Para ellos, cualquier día es bueno para tomar. (Memo, actor significativo, 35 años)

Esto permite entender por qué, al menos a nivel de representación, la casi totalidad de los actores significativos (y secundarios) se refirieron a sí mismos como "tomadores", distanciándose con esto de la categoría "borrachos", por su carga moral negativa; no obstante, algunos varones como el mismo Memo, en otros momentos admitieron que también eran "borrachos", ya fuera por beber semanalmente, por intoxicarse en cada ocasión de consumo, por las ocasionales discusiones con sus parejas o por el dinero gastado con los amigos.

Esta distinción muestra que lo que se reprueba no es el consumo per se, sino ciertos comportamientos e interacciones alcoholiza- das como los conflictos, riñas y las irresponsabilidades. Más aún, los actores consideraban que el incumplimiento de las obligaciones laborales y familiares -vinculadas directamente con representaciones sociales de género sobre la proveeduría y el trabajo doméstico y de cuidados- eran una clara muestra de quién sabía tomar y quién no. Así lo subraya Memo, "yo no puedo tomar diario como ellos [los "borrachitos"], yo tengo familia, tengo que trabajar... estaría acabado si tomara diario". Desde y en las relaciones sociales cotidianas los sujetos aprenden el qué, cuánto, dónde, cómo y con quiénes beber, así como el "buen" y el "mal" consumo de alcohol, o al menos en términos "ideales". Con lo ideal me refiero a la discrepancia entre el deber ser y lo que de hecho ocurría (lo real) respecto del consumo de alcohol en Cuzamá (aspectos que se desarrollan en la discusión).

El reconocimiento y contraste de lo ideal y lo real permite analizar estos aparentes contrasentidos como la oposición "tomador/ borracho" o la subcategoría "tomar dos", recurrentemente mencionada y que confirma la naturaleza sociocultural y colectiva de la ingesta, pero que además resalta algunas discontinuidades. "Tomar dos" expresaba la idealización de un consumo "medido", sin abusar; pero, al mismo tiempo, era un llamado a la convivencia, a la diversión y al entretenimiento en colectividad como explican los siguientes actores:

...motivos [para tomar] hay muchos, si hay partido de futbol ¡Vamos a tomar dos! Si está la fiesta del pueblo ;Vamos a tomar dos!... así nos reunimos siempre, a veces no hay motivos, es solo para estar con los amigos. (Ana, actora significativa, 27 años);

...tengo muchas amigas que trabajan, entonces cuando les toca descanso la mayoría por ser dominguito te dice, 'vamos a tomar dos'... (Alan, actor secundario, 40 años).

Ahora, y en términos reales, "tomar dos" no expresaba una unidad definida pues lo mismo 
refería a dos latas o dos vasos de cerveza, que a dos "caguamas" (botellas de 1 litro de cerveza), dos "misiles" (botellas de 1,2 litros) o incluso a dos "cartones" de cerveza (caja con 24 o 12 botellas de cerveza según su presentación). No obstante, lo que sí era consistente entre lo dicho y lo hecho era la convivencia y la diversión colectiva (regresaré a esto en un momento). "Tomar dos" constituía no solo una invitación, sino también una obligación social de regresar lo recibido anteriormente y que, según mis observaciones, se manifestaba no solo en el consumo colectivo de alcohol, sino en la comida u otros favores, y en otras relaciones además de las amicales. Así, el "tomar dos", oscilaba entre las ganas de convivir con los amigos y la conciencia del compromiso que esto podría generar como explicó un vendedor clandestino de cervezas (40 años):

\begin{abstract}
...Cuando me invitan... "vamos a tomar dos", a veces pienso "no voy" porque sé que esos dos no son dos, das primero dos y luego das otros dos... él da dos y luego vuelvo a dar dos... Por eso te digo que el que sabe tomar solo te toma dos y se va. Por decir, si somos cuatro yo doy mis dos, tomo y me voy. Pero, los que no saben tomar son los que se quedan y luego doy mis otros dos y otro dos...
\end{abstract}

No solo era difícil negarse a una invitación de consumo colectivo, sino que una vez que se reunían, el "dos" se multiplicaba y parecía difícil detenerse. Y en combinación con lo anterior, uno de los resultados más destacados y atestiguados, fue la autoreconocida incapacidad de las personas de beber solas: "¿Sola? ¡Ay no! No me gusta, no sé... ¡no sabe igual!" (Ana, actora significativa, 27 años), "nunca me ha gustado tomar solo... no sabe igual" (Kike, actor significativo, 31 años), o como experimenté con Armando (actor secundario, 40 años):

En una ocasión Armando me invitó a que lo acompañara a beber dado que ninguno de sus amigos se había reunido con él ese día; todos habían tenido trabajo o alguna situación familiar mientras que él se había ausentado de su trabajo por estar "crudo" [resaca]. Me negué en un primer momento, pero me respondió insistentemente, "¿me vas a dejar morir solo? No es bueno tomar solo", y terminé aceptando un vaso de cerveza -mismo que me sirvió dos veces. En medio de la plática me contó que cuando bebe a solas no se siente a gusto e incluso llega a sentirse triste, y no logra terminarse ni medio litro de cerveza, mientras que acompañado $y$ según pude observar, puede beber de 7 hasta 10 litros de cerveza él solo y en una misma ocasión de consumo. (Notas del trabajo de campo)

La diferencia entre el consumo solitario y el consumo colectivo estaba en que el primero era prácticamente inexistente. Todos los actores significativos y secundarios podían beber altas cantidades de alcohol en una sola ocasión -según la OMS, más de 60 gramos de alcohol puro por ocasión, es decir, más de un litro y medio de cerveza ${ }^{(1)}-$, pero no eran "capaces" de terminarse una lata de cerveza si bebían a solas (355 mililitros), según dijeron y pude observar. Era bebiendo con otras personas y no en solitario que mantenían, valoraban y reproducían esta práctica; pero, además, era también en el consumo colectivo que se experimentaba la positividad $y$, en algunos casos, la negatividad de esta ingesta (confrontaciones, pleitos, accidentes).

Considero que la incapacidad de beber en solitario como la de negarse a acompañar a otras personas a beber, junto con el disfrute y la convivencia experimentadas en la ingesta colectiva, apuntan a una especie de dependencia colectiva frente al consumo de alcohol. Al respecto, Menéndez $z^{(9,16)}$ ha señalado que los criterios e interpretaciones biomédicas sobre la dependencia-adicción alcohólica refieren, por lo general y exclusivamente, a un problema individual y de consumo solitario, el cual, sin negarlo, limita el reconocimiento de otras formas de consumo y abuso de alcohol que no responden a una dependencia química a la sustancia, 
sino al contexto y dinámica social en el que ocurre la ingesta. Asimismo, las anotaciones de Bateson ${ }^{(21)}$ sobre la relación sobriedad/ intoxicación cuestionan también la idea de la "batalla" contra del alcohol y la ilusión de "ganarle", resaltando la dependencia sistémica que se tiene al grupo, en este caso, al consumo colectivo que se configura con y desde el grupo social (dejaré para otro trabajo el desarrollo y discusión sobre la dependencia colectiva al consumo de alcohol).

El "ambiente" confirma esta dependencia y el conflicto entre el estar y el irse, entre el disfrutar y la obligación de quedarse y dar. El "ambiente" es el contexto relacional que se genera con quienes se convive y se bebe regularmente, siendo el preferido el que ocurría con "la banda", es decir, con el grupo de pares, de amigos y amigas. El "ambiente" no representaba un lugar, sino la coyuntura de un momento, de condiciones de consumo y convivencia, del tipo de compañía y de la dinámica relacional que se generaba alrededor del consumo, y que explica por qué el beber no existe ni se sostiene por la sustancia en sí misma, sino por las interacciones, efectos y afectos que en él (el "ambiente") se generan, como explica Memo:

\section{...es el ambiente y mis cuates... o sea todo. Dices "ihoy es domingo? „Vamos!", nos ponemos de acuerdo y nos vamos a algún lugar, estamos platicando, relajeando y todo. No es el sabor de la cerveza porque a veces hasta tomamos diferentes tipos de cerveza... el sabor no importa. (Memo, actor significativo, 35 años)}

Es importante consignar que este "ambiente" lo observé no solo cuando los actores se reunían a beber con sus pares, sino también cuando lo hacían solo para convivir. No obstante, y debido a diferentes circunstancias laborales y familiares, en por lo menos el $60 \%$ o $70 \%$ del total de los encuentros de estos grupos había consumo de alcohol.

El consumo de alcohol operaba tanto de forma positiva como negativa en todas las relaciones sociales, pero era con el grupo de pares y especialmente con el intragenérico, donde varones y mujeres experimentaban los principales beneficios físicos, anímicos y relacionales de este consumo. Más aún, la ingesta prolongada de alcohol entre amigos, particularmente entre varones, derivaba en expresiones de afecto (decir "te quiero") y cercanías físicas (más abrazos, caricias en el cabello, besos) que no observé con la misma frecuencia ni proximidad cuando estaban sobrios, como si fuera un "permiso" a quererse o expresárselo más cuando bebían, afectividad que entre mujeres solía ser más común, bebiendo o no. En contraste, la negatividad de esta ingesta fue más referida para las relaciones familiares y de pareja, aun cuando el alcohol también fuera parte de su ritualidad en la convivencia y distensión de los fines de semana. Dicho de otro modo, el consumo colectivo ocurría tanto con la pareja -lo menos-, la familia, la comunidad y las amistades, pero era con estas últimas con las que sucedía más, se procuraba más y se disfrutaba más.

Lo anterior no niega la existencia de tensiones o incluso de agresiones físicas -aunque en menor medida- entre varones, entre mujeres y varones, y entre mujeres en todos esos contextos tal y como pude observar; pero eran la convivencia, las interacciones no violentas y el disfrute lo que predominaba al beber con otras personas. Esto es importante ya que para comprender la continuidad del consumo colectivo en nuestras sociedades tendríamos que reconocer, como señala Cortés, que el consumo no se sostiene solo por necesidades sociales (pertenencia, cohesión grupal, etc.), sino también por necesidades subjetivo-colectivas (multifunciones) ${ }^{(8)}$, como considero que son la convivencia, la confidencia o los afectos que se intercambian en estas relaciones. Los sujetos se reúnen a beber para pasar un buen rato y no para padecerlo, de lo contario, no perduraría.

Reconociendo lo anterior, es importante no olvidar que las relaciones sociales siguen siendo vigentes e importantes para la reproducción actual de la vida social (subjetiva y colectiva), pese a sus tensiones, rupturas y cambios ${ }^{(10,12)}$. El consumo colectivo de alcohol no solo deja ver que se trata de 
un proceso configurado socioculturalmente, sino también devela la importancia que tienen las relaciones sociales entre pares, tanto o más que las familiares y/o de pareja. Más aún, el "ambiente" entre amigos y amigas -con o sin alcohol- apareció como un espacio privilegiado para determinadas convivencias, interacciones y afectos que no ocurrían de la misma forma en la interacción familiar o de pareja. Entender por qué es así, desde cuándo y qué significan para los sujetos sociales unos y otros contextos relacionales, son preguntas que merecen ser profundizadas desde abordajes interdisciplinarios.

En este mismo sentido, las categorías "saber tomar" y "no saber tomar" develan la existencia de un proceso de aprendizaje sociocultural sobre "lo bueno" y "lo malo" del consumo de alcohol, que para el caso de los actores con los que trabajé refirió, por un lado, a sus experiencias como espectadores del consumo de otras personas, particularmente durante su infancia $y$, por otro, a sus experiencias como consumidores a partir de la adolescencia (entre los 14 y 19 años de edad). Debo decir que, desde el papel de espectador, supuse que escucharía situaciones negativas vinculadas al consumo de su padre o su madre, debido en parte a la continua referencia que localmente se hacía del elevado "alcoholismo en el pueblo" (ver final de este apartado). No obstante, esto apareció solo en el relato y recuerdos de uno de los actores significativos mientras que las demás personas recordaron experiencias "neutras", es decir, ni particularmente buenas ni malas respecto de la ingesta de sus padres (la mayoría) o madres (en dos casos).

De sus aprendizajes como espectadores, los actores significativos recordaban observar el consumo comunitario en las fiestas del pueblo, y el consumo de sus padres -principalmente- en eventos familiares y comidas de fin de semana, pero resaltaban que en la mayoría de los casos estos últimos "tomaban tranquilo" y sin dejar de cumplir son sus obligaciones de proveeduría. Pero además y por encima de esto, destacaron que el consumo de alcohol era una actividad exclusiva para las personas adultas por lo que si los niños, niñas o jóvenes eran sorprendidos merodeando cerca del grupo de adultos que estaban bebiendo, se los reprendía y eran alejados inmediatamente pues el alcohol "era malo" para ellos, como también, según mencionaron actores de 50 años de edad y más, era malo que las mujeres solteras y casadas bebieran.

Las representaciones sobre cómo "tomaban antes" y "cómo toman ahora" las y los adolescentes (de 12 a 17 años) y las mujeres, apunta a cambios culturales sobre el consumo de alcohol en términos de su control y permisividad. Los actores significativos, secundarios y terciarios resaltaron una y otra vez que, en los tiempos actuales, las y los adolescentes y las mujeres habían "perdido el miedo" a beber en público, a ser vistas. Pero el hecho de que las y los adolescentes y las mujeres de "antes" no fueran vistas tomando alcohol en eventos públicos no significaba que no lo hicieran en privado o a escondidas, sino que aprendieron que esta práctica, y para estos sujetos en particular, debía ser nula o privada según criterios morales de lo "bueno" y lo "malo" basados en el género y la generación.

Sin embargo, y desde sus experiencias como consumidores, varios actores significativos (y secundarios) dejaron ver que dichas reglas no sucedieron siempre así. Por ejemplo, Liz (actora significativa, 31 años), fue sorprendida por su padre a los 16 años mientras bebía una "caguama" (botella de un litro de cerveza) con su prima, no volviendo a beber hasta que se casó a los 19 años. Memo, Armando y Kike (actores significativos), dijeron que empezaron a beber alcohol en compañía de sus pares cuando estaban en la escuela secundaria (a los 14 años, aproximadamente); recuerdan que saliendo de la escuela -o a veces escapándose antes de la hora de salida-, enviaban al que aparentaba más edad de sus respectivos grupos para comprar una o dos "caguamas" en la cantina, las metían en sus mochilas y todo el grupo se iba a tomar a escondidas a un cenote (cuerpo subterráneo y natural de agua dulce), haciendo esto una o dos veces al mes (recurrencia que no fue mencionada por ninguna de las mujeres). 
Pero, además, algunos varones como Kike o Leo recordaron haber probado la cerveza durante su infancia, ya fuera por accidente, el primero, o invitado por algún familiar, el segundo. Kike contó que cuando tenía 5 o 6 años, uno de sus tíos que estaba bebiendo junto con su papá y otro amigo, dejó una lata de cerveza a su alcance mientras se fue al baño; Kike la tomó por "curioso", según dijo, y a los minutos que el tío regresó el niño estaba ligeramente mareado por la cerveza, situación que pese a la representación de "lo malo del alcohol para los niños", provocó risas entre los adultos al darse cuenta. Esta misma práctica, pero de forma no accidental, la observé por lo menos en tres ocasiones en reuniones familiares de fin de semana en las que algún adulto (tío, tía o incluso la mamá) convidaba de unos sorbos de cerveza a sus hijos e hijas (entre 5 y 10 años de edad), generando gracia y bromas entre la audiencia.

Lo que quiero destacar con todo esto es que la representación del consumo de alcohol muestra evidentes discontinuidades y ambivalencias respecto de sus prácticas en el caso particular de la crianza de hijos e hijas: mientras, por un lado, se les dice a niñas, niños y adolescentes que el alcohol "no es bueno", e incluso se lo nombra como "vicio", por otro lado, estos mismos niños, niñas y adolescentes ven a sus padres, y en algunos casos a sus madres, divirtiéndose, conviviendo y bebiendo cervezas durante el fin de semana o en ciertas celebraciones y en compañía de otros familiares, amigos y amigas, lo que no niega que ocurran experiencias negativas para las y los infantes pero que, como he insistido, lo predominante para los actores con los que trabajé fue el consumo sin conflictos interpersonales.

En este mismo sentido, la expresión " $\mathrm{Cu}$ zamá está en 1er lugar de alcoholismo de Yucatán" fue la representación negativa más mencionada y registrada durante el trabajo de campo. Conforme avanzaba mi presencia en la comunidad y la confianza aumentaba, las personas se abrían más para hablarme también de lo positivo del beber. Esta representación, como la descrita anteriormente, funcionaba en términos formales como la idealización del deber ser y de la supuesta negatividad del alcohol, pero que al final y en términos reales, convive con representaciones y prácticas simultáneamente positivas que confirmaban los beneficios subjetivo-colectivos de esta práctica social.

\section{De desestreses, accidentes e "hígados cocidos": la ambivalencia del consumo de alcohol en el proceso de salud/ enfermedad/atención-prevención}

El disfrute, la diversión y la convivencia constituyeron dos de los principales beneficios asociados al consumo colectivo de alcohol en Cuzamá. Con todo y en términos de salud/enfermedad, este consumo también conllevaba a consecuencias negativas para la salud física, anímica y relacional. Cortés ${ }^{(8)}$ sugiere que, para un análisis complejo y relacional de la alcoholización, habría que dar cuenta no solo de sus funciones positivas y negativas, sino de la coexistencia de ambas, es decir, de sus multifunciones, ubicándolas en el contexto de las relaciones sociales y estructurales en las que surgen, y sin negar sus afectaciones (morbimortalidad). Y son la discrepancia y coexistencia de lo "bueno" y lo "malo" para la salud (las contradicciones y ambivalencias) lo que se desarrolla en este apartado.

Empezaré recuperando una de las consecuencias positivas más señaladas por los actores significativos en términos de salud física y anímica, y que apareció al mismo tiempo como el principal motivo de consumo: la oposición estrés/desestrés. Kike (actor significativo, 31 años), bebedor semanal recurrente, lo explicó de esta forma:

Yo tomo por desestrés, no por alcoholismo, porque no diario me empedo. Hay quien lo hace por gusto, yo lo hago por gusto... bueno ni tanto porque llegas y de tanto ambiente se te antoja. Cuando tenía 17, 18 años tomábamos diarios... por el estrés: 12 horas diarios parados en el trabajo, terminas de 
chambear, dices "ay mis pies", te bañas, te sientes relax, tomabas tres y ya... así descansaba; y si no tomaba una noche de esas me despertaba como con hueva, en cambio los otros días hasta me levantaba más tempranito. (Kike, actor significativo, 31 años)

También las mujeres destacaron como su principal objetivo de consumo la necesidad de relajarse y desestresarse: "el alcohol te relaja, lo sientes en el cuerpo y en todo... porque si estás triste te quita la tristeza" (Liz, 31 años). Olga (34 años) y una de sus amigas señalaron beneficios similares, "es bueno para chismear, divertirse, para el desestrés... salir de la rutina... Leí en el Facebook que es recomendable que por lo menos una vez a la semana salgas a tomar con tus amigas porque ayuda contra el estrés".

Entre las situaciones consideradas como "estresantes" para las mujeres aparecieron los problemas de pareja (infidelidades, celos, deudas), con las hijas y los hijos (salud, escuela, límites en la crianza), con sus familias de origen (estados de salud, discusiones, chismes) y sus cargas de trabajo dentro y/o fuera de sus casas. Por su parte, los varones enfatizaron los problemas laborales (conflictos con compañeros, malos salarios, tensiones), la preocupación por cumplir con sus responsabilidades familiares (proveeduría, ganar dinero) y algunos problemas con parientes o vecinos. Aunque mi estudio aborda el estrés/desestrés respecto del consumo de alcohol, considero que sería necesario continuar con la exploración de esta necesidad subjetivo/colectiva en los términos señalados por Cortés.

En muchas de mis observaciones con grupos de pares y en reuniones familiares -aunque más con los primeros-, noté que varones y mujeres se veían cómodos, divertidos y disfrutando de las interacciones que surgían mientras bebían y convivían; en esos momentos las personas no se veían agotadas ni tensas. Ocasionalmente llegué a escuchar que alguien dijera expresamente que se sentía mucho mejor tras el encuentro y consumo con sus amigos, justo después de haber tenido una semana de muchos problemas y trabajo. Así, todos los actores coincidieron en que la carga de los problemas cotidianos aminoraba a través del consumo colectivo por lo que este aparece recurrentemente como un factor positivo para la salud. Si bien la ingesta de alcohol no era la única forma de resolución de los conflictos, cuando bebían colectivamente y con su "banda", Iograban sentirse mejor.

No obstante, algunas actoras decían que, a veces y después del desestrés, experimentaban un "nuevo estrés" producto de sus responsabilidades domésticas y familiares pues estas eran un trabajo del que "no hay descanso". Pese a ello, era bebiendo juntas y no solas que encontraban una manera de enfrentar las tensiones cotidianas. En este sentido, quiero hacer una breve mención sobre la vinculación entre alcohol/relaciones violentas y no violentas, y entre el alcohol/roles de género (segundo y tercer problema de investigación de mi tesis), que por extensión no desarrollo aquí pero sí en otro trabajo ${ }^{(22)}$.

Uno de los aspectos negativos asociados al consumo de alcohol fue la violencia económica doméstica, que entiendo como el abuso cotidiano y sistemático del esfuerzo y trabajo de otras personas, generalmente mujeres, por parte de otros, generalmente varones, para mantener y reproducir la vida diaria. Esta forma de abuso cotidiano tan normalizado, evidenciaba que los varones gozaban de más tiempo, dinero y permisos (familiar como social) para reunirse y divertirse con sus amigos, mientras que las mujeres, aunque también se reunían y bebían, disponían de menos tiempo, menos dinero y menos permisos para ello.

Esto confirma lo sabido: que existe un sistema sociocultural macro y micro, que pondera los trabajos y recursos masculinos (monetarios) por encima de los femeninos (domésticos y de cuidados). Menéndez y Di Pardo ${ }^{(23)}$ han señalado que el alcohol aparece como el instrumento privilegiado de la violencia en determinados momentos y relaciones sociales, aunque sin ser su causa, develando en cambio los elementos culturales y estructurales que subyacen a estas 
"pequeñas" violencias cotidianas. La violencia económica doméstica resalta el abuso y distribución desigual de lo que Cooper nombra la economía doméstica de la reproducción ${ }^{(24)}$, y que mantienen, en lo más íntimo de nuestras relaciones sociales, las relaciones de poder y de género a través del dinero, como propone Coria ${ }^{(25)}$, y de otros recursos como evidencio en mi etnografía ${ }^{(10)}$. Así, el consumo de alcohol adopta y se adapta a una organización social preexistente, pero sin ser su causa.

Continuando con el papel del consumo de alcohol en los procesos de salud/enfermedad/atención-prevención, otro de los beneficios identificados por los actores para la salud física fue "curar la cruda", es decir, reducir el malestar físico de la resaca bebiendo nuevamente, y que fue más referida por los varones. Pero la "cruda" no se traducía necesariamente en una reducción o suspensión del consumo, y de hecho era mencionada en tono de burla. En cambio, la "cruda moral" se padecía más y refería a la culpa y arrepentimiento que experimentaban los actores cuando decían que por su ingesta habían dejado de cumplir con sus obligaciones parentales $\mathrm{o}$, en segundo lugar, porque habían flirteado o tenido algún tipo de contacto sexual con personas distintas a sus parejas (infidelidad sexual). Aunque algunas personas mencionaban que tras estos hechos "dejarían de beber" o lo harían en menor medida, esto no siempre sucedía o por lo menos no en la mayoría de quienes sentían esta culpa.

Es importante consignar que, en el caso particular de las consecuencias negativas, estas no fueron mencionadas en primera instancia por los actores, sino recién cuando se les hacía la preguntaba expresa, reconociendo más bien las afectaciones relacionales, económicas y/o conductuales. Me parece que esto responde al hecho de que la mayor parte de estas personas no habían tenido hasta ese momento afectaciones físicas de gravedad en comparación a otras consecuencias negativas que les parecían más inmediatas pero, además, a la contradictoria desestimación de la negatividad del alcohol en su salud.
Una vez hecha la pregunta, la negatividad para la salud física era identificada en: a) el deterioro del cuerpo por los desvelos y las "crudas"; b) la enfermedad y muerte por cirrosis hepática aunque esta, decían, era causada por un alto y prolongado consumo de alcohol y por "descuido", aspectos que no identificaban en sí mismos (oposición "tomador/borracho"), pero que contrastaba con las trayectorias de consumo de algunos de los actores, de hasta 15 o 20 años de consumo semanal; c) los suicidios, pero reconociendo que el alcohol no era la causa directa, aunque en prácticamente todos los casos ubicados, y sobre todo de varones, la persona había estado bebiendo o estaba alcoholizada cuando se suicidó; y d) las heridas o muertes por accidentes en vehículos de motor.

De todas estas consecuencias negativas, recupero ahora el caso de los accidentes ya que estos muestran con mucha nitidez la discontinuidad y contradicción entre lo dicho y lo hecho. Liz (31 años) admitió haber estado expuesta a accidentarse en dos ocasiones en compañía de su esposo e hijos. En ambos casos, ella y su familia habían ido a un baile en un pueblo vecino -actividad que disfrutaban con regularidad- e iban de regreso a Cuzamá. Estaban acompañados de otra familia con la que solían acompañarse a estos eventos. El conductor había bebido y seguía bebiendo mientras manejaba hasta que perdió el control del volante y se salió unos centímetros del camino pavimentado, asustando a Liz y a todos los pasajeros. A pesar del fuerte susto que esto provocó, todos continúan asistiendo por lo menos una vez al mes a estos bailes y la mayoría de las veces en las mismas condiciones, es decir, con el conductor bebiendo o incluso muy alcoholizado.

Estar cerca de morir o morir en un accidente vehicular asociado al consumo de alcohol fue algo que escuché en repetidas ocasiones y que atestigüé indirectamente durante mi trabajo de campo. En cierta ocasión fue el accidente de una de las "combis" locales (transporte público colectivo tipo Van), en el que se rumoreó que el conductor estaba "crudo", hubo varios accidentados y tres fallecidos. Otro de los actores secundarios con 
los que trabajé y al que recuerdo con especial aprecio, tuvo un accidente en motocicleta durante mi estancia, después de haber estado bebiendo toda la noche. En aquel momento, y a pesar de sus heridas, rió y minimizó el hecho cuando le pregunté qué le había pasado; dos años después, falleció en las mismas condiciones: había bebido, se subió a una motocicleta y se accidentó mortalmente. Tenía menos de 30 años y una hija.

La etnografía realizada en Cuzamá apunta una y otra vez a la existencia de contradicciones en la relación alcohol/procesos de salud/enfermedad/atención-prevención como se ha podido leer. Un último ejemplo fue lo dicho sobre la cirrosis hepática alcohólica. Ningún actor o actora significativa dijo estar padeciendo síntomas de esta enfermedad, y las ocasiones en las que les pregunté directamente si creían que su forma de beber podía llegar a afectar su salud obtuve respuestas negativas. Las mujeres destacaban este riesgo en otras personas, pero lo desestimaban en sí mismas, justificándose en el hecho de que no bebían tanto ni tan frecuentemente -lo cual en términos comparativos a los varones era cierto. Ana (27 años) dijo que uno de sus primos había muerto un par de años de atrás por esta causa, "tenía cirrosis... se le coció su hígado; no comió por un mes, solo tomaba. Así hay varios que han muerto de eso aquí".

Por su parte, los varones minimizaron el potencial riesgo para su salud y hasta bromearon diciendo que, en caso de enfermarse de cirrosis, "de algo me tengo que morir, ¿no?", como le escuché decir a Armando. Uno de los mejores amigos de Kike (31 años), Miguel (actor secundario, 36 años) me contó durante una reunión en su casa que había empezado a beber a los 14 años. Para cuando tenía 26 su ingreso a un nuevo trabajo lo obligó a realizarse estudios generales de sangre, resultando lo siguiente:

¡Todo salió mal! Triglicéridos, colesterol, ácido úrico... iTodo! Chinga, la verdad me asustó lo que me dijo el doctor, sí me preocupé... pero luego pensé ¡Chingue su madre! Me puse a tomar otra vez y se me olvidó. Solo hay una vida, ¿no?
Hay que disfrutarla. La neta a mí me gusta mi vida tal como es... y yo así me voy a morir. (Miguel, actor secundario, 36 años)

Miguel ignoró sus resultados y a la fecha continúa bebiendo por lo menos dos días a la semana en eventos abiertos, pero sobre todo en su casa, en compañía de amigos y a veces de familiares. En la mayoría de estas ocasiones bebe de dos hasta cinco o seis horas y por lo menos tres litros de cerveza y, en ocasiones, hasta diez.

De este modo, las mujeres pero más los varones no parecían ser consecuentes con su reconocimiento de los riesgos que la ingesta de alcohol pudiera tener en su salud, poniendo en evidencia una clara ambivalencia respecto al consumo pues mientras, por un lado, se reconocía y padecía su negatividad en el deterioro del cuerpo, en las "crudas", en el riesgo a la cirrosis y a morir en un accidente vehicular, por el otro, coexistía con el disfrute de su positividad a través del desestrés, el relajamiento, la diversión y la convivencia. Para ejemplificar lo anterior, describo lo que considero una de las situaciones paradigmáticas de esta ambivalencia, presenciada durante mi observación participante del martes de carnaval de 2017 en Cuzamá:

El desfile de los carros alegóricos ya había terminado y toda la gente estaba congregada en los bajos del Palacio Municipal, donde tocaba un conjunto local. Eran las 11 de la mañana y entre disfraces, accesorios y juguetes, varones y mujeres de todas las edades caminaban y se saludaban. Jóvenes y adultos consumidores tenían en sus manos latas de cerveza, botellas de "caguamas" y "misiles" o vasos de un litro de cerveza. El ambiente era notorio y predominantemente de diversión. Mientras caminaba fui encontrándome con distintos actores. Leo estaba reunido con un grupo de siete amigos entre varones y mujeres; todos los varones bebían cervezas y, de las mujeres, solo una no lo hacía; Leo y dos de sus amigos estaban disfrazados. 
Ana estaba con su esposo e hijo a quien había disfrazado también; ella y su esposo bebían una michelada que este había comprado, y de la cual insistieron en convidarme. Olga estaba con su grupo de amigas y entre todas habían comprado un par de "six", pero además, les habían regalado otros dos litros de cerveza según me presumieron. Todas ellas estaban disfrazadas y habían sido parte de una de las comparsas que horas antes había bailado en la calle principal del pueblo; gritaban, bailaban y reían en un claro ambiente de diversión. Armando ya estaba algo alcoholizado cuando me lo encontré, lo que sugiere que había empezado a beber al menos un par de horas antes de que empezara el desfile o tal vez no había dejado de beber desde la noche anterior. Al verme me abrazó y me dio una de las latas de cerveza que había comprado; en ese momento estaba con Kike y otros dos amigos. Le agradecí la lata pero me negué diciéndole que todavía era muy temprano, que apenas acababan de dar las 12 del día -la verdad es que no tenía antojo de beber a esa hora-, pero entonces me insistió y desestimando lo que le había dicho me respondió, "es carnaval, y en el carnaval todo se vale", expresión que luego escucharía durante la tarde otras dos veces más, una de ellas de parte de un funcionario público que al inicio de mi trabajo de campo me había hablado predominantemente de la negatividad del alcohol. Finalmente, me encontré con Memo y con cuatro amigos suyos; estaban en una esquina del Palacio Municipal y además de latas de cerveza habían dispuesto una nevera de unicel con hielos, "mixers" y tres botellas de licor (vodka, whisky y tequila). Al verme me invitaron un trago del "coctel" que uno de ellos acababa de preparar; les dije que me parecía que se habían preparado bien para asistir al carnaval y entonces Memo respondió: "ya sabes, siempre". Hacia las dos de la tarde calculo que había más de 1.000 personas en los bajos de Palacio. La mayoría de los varones y mujeres adultas estaban bebiendo, lo mismo que varios jóvenes estudiantes del COBAY [Colegio de Bachilleres del Estado de Yucatán] y algunos de la secundaria según reconocí; a pesar de ser menores de edad nadie decía nada. Pero el momento que me pareció culmen de este "gran ambiente de consumo colectivo" fue cuando el conjunto musical interpretó la canción "Yo quiero chupar" de los Súper Lamas. En ese instante muchas personas comenzaron a brincar y alzar sus vasos, botellas y latas de cerveza al ritmo de la canción; le daban tragos prolongados y las pasaban a sus amigos y amigas. Gritaban al unísono, bailaban y seguían bebiendo. Me pareció que la canción y lo que esta decía reflejaban perfectamente el sentir de los actores y de la población en general en ese momento sobre los beneficios del consumo de alcohol, y por encima y a pesar de sus afectaciones. (Notas del trabajo de campo)

Para enfatizar lo anterior, transcribo a continuación la canción referida en mis notas de campo.

\section{Canción "Yo quiero chupar" (Grupo Súper Lamas, 2014)}

No quiero seguir sentado no me quiero ir a dormir No quiero estar encerrado yo me quiero divertir.

Yo quiero chupar y con la banda ir a tomar Yo quiero cerveza hasta que explote la cabeza No me importaría vivir de fiesta todo el día Toda la semana hasta las seis de la mañana.

Cantando con mis amigos no voy a parar la farra Que me sirvan otra chela que esta noche no se para Bien loco en la madrugada con la cabeza dando vueltas Yo quiero seguir tomando que no acabe esta fiesta

Yo quiero chupar y con la banda ir a tomar...

Bien loco en la madrugada me sigue la policía Yo quiero seguir bailando que no acabe esta alegría 
Yo quiero chupar y con la banda ir a tomar...

Que me pasen otra chela y que cambien este ritmo.

Yo quiero chupar, con Super Lamas a bailar

Yo quiero cerveza hasta que explote la cabeza

No me importaría vivir de fiesta todo el día

Toda la semana hasta las 6 de la mañana.

Fuente: Youtube

Considero que la letra de esta canción, junto con las interacciones y conductas observadas aquel día -como en otras ocasiones-, confirman que, aunque los actores conocen el riesgo que este consumo puede traerles, y especialmente el abuso colectivo, lo minimizan o lo ignoran al anteponer su positividad, lo que al mismo tiempo corrobora la prevalencia de sus beneficios para la salud integral, razón por la que esta práctica persiste y se reproduce pese a sus afectaciones.

\section{DISCUSIÓN}

En este texto he tratado de abordar la complejidad del proceso de alcoholización a partir de las consecuencias negativas, positivas $y$, especialmente, las ambivalentes del consumo de alcohol en la salud y relaciones sociales de varones y mujeres de un municipio de Yucatán (México). Para ello, he dado cuenta de las representaciones y prácticas sociales de ambos sexos, analizando las continuidades y especialmente las discontinuidades entre lo dicho y lo hecho cuando beben, entre "lo bueno" y "lo malo" del alcohol, entre el "saber tomar" y el "no saber tomar". Los resultados indican aparentes contradicciones que en realidad apuntan a un sistema de saberes sociales (valores, creencias, normas y prácticas) que reconoce simultáneamente la positividad y negatividad de esta ingesta, y que expresa la multifunción que reproduce y mantiene no solo sus beneficios subjetivocolectivos, sino también sus perjuicios para la salud ${ }^{(8)}$.
Mi revisión de antecedentes ${ }^{(10)}$ muestra que son pocas las investigaciones contemporáneas, en general, y antropológicas, en particular, que han abordado lo anterior, como pocos son también los estudios que describen no solo las creencias (representaciones) sino las prácticas (observación) de los conjuntos sociales respecto de este proceso, sea por motivos financieros, de infraestructura o ideológicos. Pese a lo anterior, existen algunas etnografías y propuestas teóricas que me permitirán establecer esta discusión que centraré en la ambivalencia. Esta discusión es un proceso abierto ya que es posible que existan otros trabajos que desconozca o a los cuales no haya tenido aún acceso, y que sin duda enriquecerían aún más este análisis.

Cortés señaló que es la multifunción positiva y negativa del consumo de alcohol lo que asegura la continuidad de la alcoholización en tanto proceso sociocultural( ${ }^{(8)}$, produciendo y reproduciendo los saberes que lo significan. Las trabajos que retomo muestran en mayor o menor medida lo anterior y, más allá de nuestras diferencias en los planteamientos, cómo aún dentro de una misma sociedad e incluso grupo social (amigos o familia) no existe un solo sistema cultural que oriente las representaciones (normas, creencias, ideas) y prácticas (conductas, comportamientos) de los sujetos con relación a lo que se considera un consumo adecuado o desviado de alcohol, o que identifique con precisión quiénes "saben o no saben tomar".

En la década de 1980, M. Jean Gilbert ${ }^{(26)}$ estudió las creencias y comportamientos sobre el alcohol, de mujeres y varones mexicano-americanos residentes en California (EEUU). De sus resultados sobresale que ambos sexos distinguían entre los comportamientos aceptados (sin embriagarse, para socializar, celebrar, darse un "respiro" del trabajo, etc.) de los desviados (conflictos interpersonales, irresponsabilidades); sin embargo, también observó que estas creencias no siempre se correspondían con los comportamientos alcoholizados, según el contexto y situación social. Contextos diferentes implicaban normas y sanciones diferentes que en última instancia operaban en la forma 
de consumir alcohol y de comportarse de unos y otras.

Por ejemplo, en eventos más privados y familiares se veía mal la embriaguez de los hombres -aunque se toleraba-, mientras que las mujeres solían beber menos en comparación a cuando bebían entre amigos y amigas, reprobándose en ambos espacios los conflictos interpersonales. En cantinas y bares donde la clientela era predominantemente masculina, la embriaguez de los varones era bien vista, aprobada e impulsada, así como las interacciones y hasta insinuaciones sexuales que hacía a las meseras, pero en ciertos bares urbanos de clase media, lo anterior era sancionado. Al respecto Gilbert señala que:

...las normas que guían el consumo de alcohol de los mexicano-estadounidenses son muy diferentes de situación en situación de consumo, dependiendo de quién está presente (rangos de edad, sexo, clase y etnicidad de las demás personas), y el tipo de actividades en las que los consumidores están participando. Así, lo que podría ser considerado como una cantidad inapropiada o desviada de consumo de alcohol o de comportamientos inapropiados en un lugar particular con un grupo particular de personas [...], puede no serlo en otro. [Traducción libre de: ...the norms that guide Mexican-American drinking behavior are in fact very different from situation to situation, depending on who is present in the drinking setting (age range, sex, class, and ethnicity of participants) and the type of activities in which the drinkers are participanting. Thus, what might be considered inappropriate or deviant quantities of alcohol consumed or inappropiate behaviors in one setting among a particular group [...] may noy be so considered in another. $]^{(26)}$

La autora concluye que para la población mexicano-americana no existe un solo sistema de creencias, normas o comportamientos con relación al uso de alcohol, sino que ciertos comportamientos alcoholizados como la embriaguez y el cortejo sexual eran sancionados negativamente en determinados contextos por razones de clase (estatus), pero aceptados y promovidos en otros por razones de género (masculinidad). También resalta que esta variabilidad no fue exclusiva a los varones mexicano-americanos, observándose también en los angloamericanos.

Lo anterior también fue observado en Cuzamá a través de la oposición "tomador/borracho" y de las expresiones "tomar tranquilo", "tomar sin pasarse" y "tomar dos", subcategorías explicativas del "saber y no saber tomar" que, de forma similar a la población estudiada por Gilbert, dan cuenta del reconocimiento de más de un tipo de consumo social de alcohol, según con quiénes y en qué situaciones se bebe. Los actores con los que trabajé sabían que "tomar dos" con la familia significaba, por lo general, comprar solo un par de "caguamas" para relajarse y disfrutar de una buena comida de fin de semana, mientras que la misma "medida" con los amigos o amigas se traduciría en más horas y litros de consumo, y no se diga para el caso de ciertas fiestas comunitarias como el carnaval.

Pero, además, lo que quiero subrayar es que no solo se trata de una variación intencional de creencias y prácticas sociales respecto del consumo según la situación social, como plantea Gilbert, sino que devela un sistema sociocultural más amplio que se caracteriza por su discontinuidad y ambivalencia, es decir, por reconocer y experimentar simultáneamente "lo bueno" y "lo malo" aun y cuando no siempre seamos conscientes de ello, característica que va más allá del consumo de alcohol. Esto fue particularmente evidente en Cuzamá a través del proceso de salud/ enfermedad/atención-prevención cuando se reconocía este consumo como un potencial perjuicio para la salud física (accidentes, crudas, cirrosis), anímica (cruda moral) y relacional (conflictos, tensiones), pero también y al mismo tiempo, como un beneficio (desestrés físico, mental y anímico, relajación, expresión de afectos, diversión, convivencia, etc.). Una aparente incongruencia y contradicción pero que, recordando las palabras de Berlinguer ${ }^{(27)}$, no sería de extrañar si partimos del 
supuesto de que los procesos de salud/enfermedad/atención-prevención llegan a constituirse como espías de las contradicciones de un sistema (histórico, político-económico, cultural y/o ideológico).

La multifunción subjetivo-colectiva del consumo de alcohol, en palabras de Cortés, expresa su contradicción en la salud/enfermedad y su complejidad aumenta, pues en algunos lugares o en ciertas relaciones y contextos los sujetos o grupos se decidirán por el alcohol, dados sus beneficios económicos o para ciertas posiciones de poder o de pertenencia social ${ }^{(8,17)}$, aspecto que también se observó en campo, donde pese a la representación "Cuzamá está en primer lugar de alcoholismo en Yucatán", por lo menos entre una cuarta y tercera parte de la población económicamente activa del municipio obtenía sus ingresos de la distribución y/o venta de bebidas alcohólicas.

Otro ejemplo contemporáneo de la ambivalencia entre el consumo de alcohol y los procesos de salud/enfermedad/atenciónprevención sucedió en el marco de la actual contingencia sanitaria por Covid-19. Bajo argumentos de protección a la salud de las familias yucatecas, incluyendo la prevención de la violencia doméstica, el gobierno del estado de Yucatán decretó a principios de abril de 2020 la prohibición de la venta de bebidas alcohólicas en toda la entidad, la llamada "Ley Seca"(28), y que originalmente duraría hasta finales de abril pero que terminó por extenderse hasta fines de mayo, generando opiniones y prácticas ambivalentes en la población. El caso más dramático de esto fue la muerte de por lo menos 16 personas (mayoría varones) en Yucatán, durante el mes de mayo, tras beber alcohol adulterado, la mayoría estaba bebiendo en compañía de otras personas cuando esto ocurrió. Para mediados del mismo mes, el número de personas muertas por consumo de alcohol adulterado a nivel nacional, alcanzó casi las 160 defunciones, en municipios y estados que también aplicaron esta prohibición ${ }^{(29,30)}$.

La ambivalencia del consumo de alcohol ha sido señalada en por lo menos una parte de los estudios socioculturales, pero como ocurre con muchas cosas, suelen "olvidarse", como diría Menéndez ${ }^{(31)}$. Horton apuntaba en la década de 1940 que:

[El consumo de alcohol] involucra una paradoja que está implícita en el hecho de que, no obstante todas sus peligrosas consecuencias [...] ni siquiera la pena de muerte ha sido capaz de prevenir su uso. [...] Se advierte un contradictorio agregado de actitudes que Myerson caracteriza como "la ambivalencia de la actitud y la opinión humana" hacia la bebida. ${ }^{(19)}$

En esos mismos años, Bacon analizaba que la creciente complejidad de las sociedades podía ser un factor significativo en las relaciones sujeto/alcohol, donde el consumo aumentaría los peligros para sí y para la sociedad, y "[aunque] podrá tener otros efectos menos deseables, [...] en ese momento [cuando se bebe] son irrelevantes" ${ }^{\prime \prime(32)}$. En México, en la década de 1960, Pozas ${ }^{(33)}$ muestra esta ambivalencia en la palabra posch (bebida alcohólica local) entre los indígenas de Chamula, la cual significaba simultáneamente aguardiente y remedio medicinal; también a nivel nacional, y hacia finales de la década de 1980, Ravelo dio cuenta de la positividad y negatividad del consumo de alcohol, inherente en los procesos de socialización en la vida familiar y comunitaria, a través de la percepción de niños y niñas ${ }^{(34)}$. En las décadas de 1970 y 1980, estudios longitudinales con familias de EEUU, apuntaban también a la discrepancia entre las normas ideales y reales sobre el consumo de alcohol ${ }^{(17)}$.

¿Cómo entender esta ambivalencia en los saberes sociales respecto del consumo de alcohol y sus consecuencias? Una de las propuestas teóricas que a mi parecer permite entender con mayor claridad lo anterior es la elaborada por Linton ${ }^{(35)}$, respecto de las pautas culturales, las que entiende como los patrones aprendidos por y en cada grupo social y que orientan a sus sujetos en cómo actuar y reproducir en última instancia a la sociedad misma. Estas pautas se expresan de diferentes formas, siendo las más importantes las reales y las ideales. Las primeras son las actitudes y 
acciones manifiestas de los sujetos, es decir, las que en los hechos reproducen lo social; las segundas son abstracciones creadas por los propios sujetos y que dan cuenta del consenso de opinión sobre la forma en la que debemos comportarnos en determinadas situaciones. Pero sucede, advierte Linton, que lo ideal no siempre se corresponde con lo real -lo que decimos que debemos hacer con lo que de hecho podemos o queremos hacer-, ya sea por la dificultad o imposibilidad de actuar o vivir lo ideal, o por tratarse de un valor sociocultural que, pese a su cuantía o consenso, nunca se concreta, se ignora o hasta se infringe más de lo que se cumple.

Frente a esto, algunas preguntas permanecen: $¿ A$ qué responde la ambivalencia del consumo de alcohol y sus consecuencias, en cada grupo y contexto social determinado? ¿Qué necesidades subjetivo-colectivas son satisfechas en los diferentes contextos relacionales de consumo social? ¿Por qué es a través del consumo colectivo, y preferentemente en el contexto relacional entre pares, que se experimentan más ciertos beneficios (desestrés, convivencia, diversión, expresividad afectiva, etc.) y no en otros? Existen algunos trabajos que ofrecen hipótesis explicativas al respecto.

Una de estas hipótesis, al menos para la primera pregunta, se podría encontrar en el trabajo de Herd ${ }^{(36)}$ con relación a lo que identificó como la "ambigüedad" de las normas del consumo de alcohol en población afroamericana. La investigadora describe que no existe un consenso cultural sobre el valor de este consumo pues al mismo tiempo que expresa placer también evoca sentimientos negativos. Herd considera que una de las principales razones de esta ambigüedad y conflicto cultural entre la población afroamericana se encuentra en el movimiento de temperancia de EEUU. En las últimas décadas del siglo XIX, cuando el espíritu prohibicionista estadounidense emergía, la comunidad afroamericana fue una de sus principales impulsoras, organizándose a través de sus pequeñas comunidades religiosas debido, en gran medida, a que el consumo de alcohol y el alcoholismo eran vistos como una expresión y extensión de la esclavitud, al mantener a las personas de color en una posición de dominio y opresión.

En cuanto el movimiento de temperancia comenzó a cobrar fuerza entre la población angloamericana, los prohibicionistas afroamericanos fueron discriminados y se vieron obligados a desistir en su participación, generando molestia, y algunos comenzaran a beber de nuevo. Después de la Ilamada "gran migración" muchas de estas personas que provenían de comunidades pequeñas y religiosas, rápidamente comenzaron a participar de la vida nocturna de los clubes en las grandes ciudades, empleándose como músicos y bailarines. Fue durante este periodo que Herd ${ }^{(36)}$ considera que se inició el elevado consumo de alcohol en la población afroamericana de EEUU. La autora indica que incluso la misma iglesia protestante, tan fuertemente moral con relación al alcohol y otros vicios, comenzó a relajar sus propias normas para conciliar el hecho de que varios de sus miembros o familiares ganaban dinero del embotellamiento de alcohol o de las apuestas.

El movimiento de temperancia tuvo un correlato importante en México, particularmente, en el estado de Yucatán. Aunque no es el objetivo de este trabajo realizar un análisis histórico, retomo brevemente el estudio de Márquez ${ }^{(37)}$ quien documentó que el consumo de alcohol en Yucatán representó, a principios del siglo XX, una suerte de chivo expiatorio al que se culparía de que la población maya y campesina no sumara lo suficiente al desarrollo y progreso porfirista de la época, justificando el despliegue de toda una serie de políticas orientadas al autogobierno, la abstinencia y el control de sí, impulsadas fuertemente por la entonces Liga de Acción Social.

Si bien no contamos con información suficiente que establezca una relación entre este proceso histórico y las formas de consumo actual de la población maya-yucateca, rural y urbana, el reciente caso de la "Ley Seca" en el marco del Covid-19 muestra una herencia histórico-ideológica -y también su contradicción, en palabras de Berlinguer-, al depositar en el consumo de alcohol, el 
principal factor causal de importantes problemas de salud pública en el estado. Pero, además, pudiera estar revelando el conflicto moral (representación ambivalente) que existe entre la idea de que quienes no beben o beben "poco" -como si tuviéramos datos precisos al respecto- son personas más responsables o incluso "buenas" (pauta ideal, el deber ser), que las que admiten y disfrutan del beber regularmente (pauta real), lo que fue confirmado con la polarización que la prohibición generó en el estado.

Este conflicto moral lo experimenté también durante el trabajo campo al ser interpelado por algunos actores terciarios de Cuzamá (la directora de una de las escuelas de educación básica), desde mi rol de "investigador del alcoholismo" y de "psicólogo". Era como si la imagen que tenían de mí (venir de fuera, tener estudios universitarios y ser psicólogo), fuera incompatible con mi consumo público de alcohol, como si lo primero fuera "lo bueno" y lo segundo "lo malo" y, en consecuencia, no se correspondieran con el ideal del consumo de alcohol y sus consecuencias.

En suma, considero que la herencia de la antropología del alcoholismo y, posteriormente, de la antropología médica crítica, nos orienta a reconocer la ambivalencia que caracteriza al consumo de alcohol y a sus consecuencias en los conjuntos sociales, para entonces poder avanzar en la comprensión de la complejidad del proceso de alcoholización. Aún prevalecen muchas preguntas que necesitan ser profundizadas, como las propuestas líneas arriba. Las discontinuidades al interior de las representaciones, de las prácticas, y entre las representaciones y las prácticas, no deben desestimar o llevarnos a pensar que son contradicciones que no merecen la pena ser estudiadas. Por el contrario, nos confirman su existencia y nos urgen a un estudio cada vez más complejo(8) y relacional ${ }^{(12)}$.

En este sentido, vale la pena retomar lo que Menéndez ${ }^{(10)}$, considera como tareas pendientes en el estudio del proceso de alcoholización: 1) reconocer su complejidad en términos históricos, político-económicos e ideológico-culturales; 2) describir y analizar su positividad, no solo en términos de homogeneidad cultural, sino también dando cuenta de las tensiones, discontinuidades y ambivalencias al interior de un mismo grupo, así como de los beneficios económicos y subjetivo-colectivos; 3) no negar ni olvidar que pese a lo anterior, el consumo de alcohol ha constituido un importante problema de salud pública en nuestra región; y 4) priorizar el estudio no solo de lo que se dice (representaciones sociales) sino también de lo que de hecho se hace cuando se bebe (prácticas sociales).

\section{REFLEXIONES Y ANOTACIONES FINALES (A MODO DE CONCLUSIONES)}

La información hasta aquí presentada muestra que en Cuzamá -aunque probablemente en muchas otras comunidades de Yucatán y México- el consumo de alcohol se representa predominantemente desde su negatividad, en términos ideales, para la salud física, anímica y relacional. No obstante, los sujetos también reconocen y experimentan sus consecuencias positivas, principalmente en el consumo colectivo y a través de relaciones que les son significativas y afectivamente cercanas, como el grupo de pares. Ello no niega la negatividad del consumo, sino que incluso la evidencia, pero lo que destaca es que, más allá de sus riesgos, el consumo colectivo de bebidas alcohólicas constituye para la mayoría de los conjuntos sociales una representación y práctica social tanto positiva como negativa, y es esta ambivalencia la que en gran medida asegura su continuidad y reproducción.

La negatividad de la bebida, en términos de dependencia y de abuso, es una realidad innegable, pero que afecta a un porcentaje de la población que en última instancia es menor al de la mayoría de los conjuntos sociales que se asume y reconoce como bebedores habituales, y que es donde se expresan las principales afectaciones en términos de 
morbimortalidad y de relaciones sociales (accidentes, suicidios, cirrosis hepática alcohólica, violencias alcoholizadas), siendo además en y desde las relaciones sociales donde se configuran sus significados y prácticas.

Por ello, es necesario reconocer que no todo consumo es siempre problemático y que su positividad puede explicar, al menos en parte, por qué no parece disminuir de forma significativa -en comparación a otras sustancias como el tabaco-, e incluso aumenta en algunos sectores sociales (mujeres y jóvenes).
Finalmente, el estudio del consumo de alcohol y de sus consecuencias urge de una aproximación que no solo explore lo que los sujetos dicen (representaciones) sino lo que de hecho hacen (prácticas) cuando beben, identificando con ello continuidades, discontinuidades y ambivalencias que nos ofrezcan un panorama más claro, menos moralizador, menos dicotómico y menos castigador de una actividad que aparece ampliamente normalizada en la vida social cotidiana.

\section{AGRADECIMIENTOS}

La realización de esta investigación fue resultado de mi formación en el programa doctoral de antropología del Centro de Investigaciones y Estudios Superiores en Antropología Social (CIESAS-CDMX, promoción 20152019), como parte de la línea de Antropología Médica. Mi participación y finalización en dicho programa fueron posibles gracias a la beca económica otorgada por el Consejo Nacional de Ciencia y Tecnología (CONACYT), al apoyo técnico y administrativo del CIESAS-CDMX, y a la formación recibida en los seminarios en general y de la línea de antropología médica, en particular, destacando de manera especial la dirección del Dr. Eduardo Menéndez Spina. Por último, y de forma especial, agradezco a todas las personas de Cuzamá por su calidez, aceptación y apoyo y, particularmente a quienes participaron informada y voluntariamente en la investigación.

\section{REFERENCIAS BIBLIOGRÁFICAS}

1. World Health Organization. Global status report on alcohol and health 2018 [Internet]. Geneva: World Organization Health; 2018 [citado 1 jun 2019] Disponible en: https://tinyurl.com/wblabt4.

2. Villatoro-Velázquez JA, Reséndiz-Escobar E, MujicaSalazar A, Bretón-Cirett M, Cañas-Martínez V, Soto-Hernández I, Fregoso-Ito D, Fleiz-Bautista C, Medina-Mora ME, Gutiérrez-Reyes J, Franco-Núñez A, Romero-Martínez M, Mendoza-Alvarado L. Encuesta Nacional de Consumo de Drogas, Alcohol y Tabaco 2016-2017: Reporte de Alcohol [Internet]. Ciudad de México: Instituto Nacional de Psiquiatría Ramón de la Fuente Muñiz;
2017 [citado 1 jun 2019]. Disponible en: https://tinyurl. com/yxsuvgu9.

3. Medina-Mora ME, Villatoro-Velázquez JA, FleizBautista C, Téllez-Rojo MM, Mendoza-Alvarado LR, Romero-Martínez M, Gutiérrez-Reyes JP, Castro-Tinoco M, Hernández-Ávila M, Tena-Tamayo C, Alvear-Sevilla C, Guisa-Cruz V. Encuesta Nacional de Adicciones 2011: Reporte de Alcohol [Internet]. México DF: Instituto Nacional de Psiquiatría Ramón de la Fuente Muñiz; 2012 [citado 10 ene 2016]. Disponible en: https://tinyurl.com/ yywb4ywv.

4. México, Servicios de Salud de Yucatán. Encuesta Estatal de Adicciones, 2014-2015 [Internet]. Mérida, Yucatán: Secretaría de Salud, Servicios de Salud de Yucatán; 2015 [citado 10 jun 2016] Disponible en: https:// tinyurl.com/y3rmmpqj.

5. México, Servicios de Salud de Yucatán. Encuesta Estatal de Adicciones 2005 [Internet]. Mérida, Yucatán: Secretaría de Salud, Servicios de Salud de Yucatán; 2005 [citado 10 jun 2016] Disponible en: https://tinyurl.com/ y2qrvooa.

6. Dirección General de Epidemiología. Casos por entidad federativa de Enfermedades No Transmisibles hasta la semana epidemiológica 51 del 2017. Boletín Epidemiológico [Internet]. 2017;34(52) [citado 12 jun 2018]. Disponible en: https://tinyurl.com/y5tkueqk.

7. Instituto Nacional de Geografía. México: Principales causas de mortalidad por residencia habitual, grupos de edad y sexo del fallecido [Internet]. 2017 [citado 12 jun 2018]. Disponible en: https://tinyurl.com/yxfphu2n. 
8. Cortés B. La funcionalidad contradictoria del consumo colectivo de alcohol. Nueva Antropología. 1988;10(34): 157-185.

9. Menéndez E. Morir de alcohol: Saber y hegemonía médica. Buenos Aires: Universidad Nacional de Lanús; 2020. doi: 10.18294/9789874937490.

10. Moreno S. Entre "saber tomar" y "no saber tomar": consumo de alcohol y consecuencias positivas, negativas y ambivalentes en la salud, recursos económicos y relaciones sociales de varones y mujeres de un municipio de Yucatán. [Tesis doctoral]. México: Centro de Investigación y Estudios Superiores en Antropología Social; 2019.

11. Singer M. Reinventing medical anthropology: Toward a critical realignment. Social Science \& Medicine. 1990;30(2):179-187. doi: 10.1016/0277-9536(90)900787.

12. Menéndez E. De sujetos, saberes y estructuras: Introducción al enfoque relacional en el estudio de la salud colectiva. Buenos Aires: Lugar Editorial; 2009.

13. Comisión Nacional para el Desarrollo de los Pueblos Indígenas, Ciencia Social Alternativa. Me muero por tomar [Video]. 2012 [citado 15 ago 2019]. Disponible en: https://tinyurl.com/y4ugtr5y.

14. Comisión Nacional para el Desarrollo de los Pueblos Indígenas, Ciencia Social Alternativa. Mujeres de Cuzamá pensando en una comunidad mejor [Internet]. 2012 [citado 15 ago 2019]. Disponible en: en https:// tinyurl.com/yyq57ovz.

15. Wagner W, Hayes N. Métodos en investigación de las representaciones sociales. En: Flores Palacios F, (ed.). El discurso de lo cotidiano y el sentido común: la teoría de las representaciones sociales. Barcelona: UNAM, Anthropos; 2011. p. 281-318.

16. Menéndez E. Antropología del alcoholismo en México: Los límites culturales de la economía política 19301979. México: CIESAS, Ediciones de La Casa Chata; 1991.

17. Heath D. Anthropology and alcohol studies. Annual Review of Anthropology. 1987;16:99-120.

18. Menéndez E, Di Pardo R. De algunos alcoholismos y algunos saberes: Atención primaria y procesos de alcoholización. México: Centro de Investigaciones y Estudios Superiores en Antropología Social; 1996.

19. Horton D. Las funciones del alcohol en las sociedades primitivas. En: Menéndez Spina E. Antropología del alcoholismo en México: Los límites culturales de la economía política 1930-1979. México: CIESAS, Ediciones de La Casa Chata; 1991. p. 35-64.

20. Menéndez E. Poder, estratificación social y salud: Análisis de las condiciones sociales y económicas de la enfermedad en Yucatán. 2a ed. Tarragona: Universitat Rovira I Virgili; 2018.

21. Bateson G. Pasos hacia una ecología de la mente. Buenos Aires: Lohle-Lumen; 1998.
22. Moreno S. Entre la dominación y la vulnerabilidad: poder, padecer y privilegios masculinos: El caso del consumo de alcohol en las relaciones sociales cotidianas. En: Peña Sánchez YE, Hernández Albarrán L, (coords.). Cuerpos, géneros y sexualidades. Contextos mesoamericanos y contemporáneos. México: Instituto Nacional de Antropología e Historia. (En prensa, 2020).

23. Menéndez E, Di Pardo R. Violencias y alcohol: Las cotidianeidades de las pequeñas muertes. Relaciones. 1988; 19(74):37-71.

24. Cooper JA. Preguntas frecuentes en torno al estudio del género y economía. Economía Informa. 2004;(334):511.

25. Coria C. El dinero en la pareja: Algunas desnudeces sobre el poder. Buenos Aires: Grupo Editorial Latinoamericano; 1989.

26. Gilbert MJ. Mexican-americans in California: Intracultural variation in attitudes and behavior related to alcohol. En: Bennett L, Ames G, (eds.). The American experience with alcohol: Contrasting cultural perspectives. New York: Plenum Press; 1985. p. 255-277.

27. Menéndez E. Las enfermedades ¿son solo padecimientos?: biomedicina, formas de atención "paralelas" y proyectos de poder. Salud Colectiva. 2015;11(3):301330. doi: 10.18294/sc.2015.719.

28. Moreno S. Razones y sinrazones de la "Ley Seca". Diario de Yucatán [Internet]. 4 may 2020. Disponible en: https://tinyurl.com/y6de5vml.

29. Yucatán Ahora. Dos muertos más por alcohol adulterado: ya son 16 defunciones en esta ley seca. Yucatán Ahora. [Internet]. 22 may 2020. Disponible en https:// tinyurl.com/y44unylt.

30. Miranda J. La otra epidemia en México: morir por alcohol adulterado. El Universal [Internet]. 20 may 2020. Disponible en: https://tinyurl.com/yygkq8sd.

31. Menéndez E. De racismos, esterilizaciones y algunos otros olvidos de la antropología y la epidemiología mexicanas. Salud Colectiva. 2009;5(12):155-179. doi: 10.18294/sc.2009.258.

32. Bacon S. El alcohol y la sociedad compleja. En: Menéndez E. Antropología del alcoholismo en México: Los límites culturales de la economía política 1930-1979. México: CIESAS, Ediciones de La Casa Chata; 1991. p. 65-86.

33. Pozas R. El alcoholismo y la organización social. En: Menéndez E. Antropología del alcoholismo en México: Los límites culturales de la economía política 19301979. México: CIESAS, Ediciones de La Casa Chata; 1991. p. 189-197.

34. Ravelo P. Ambivalencia y contradicción: reproducción del proceso de alcoholización en los niños. Nueva Antropología. 1998;10(34):81-109.

35. Linton R. Cultura y personalidad. México: Fondo de Cultura Económica; 1945 
36. Herd D. Ambiguity in black drinking norms: an ethnohistorical interpretation. En: Bennett L, Ames G, (ed.). The American experience with alcohol: Contrasting cultural perspectives. New York: Plenum Press; 1985. p. 149-170.
37. Márquez A. Las políticas sobre el consumo de alcohol: Ciencia, orden y voluntad, Mérida, Yucatán siglos XIX y XX. [Tesis de Maestría], Mérida, Yucatán: Facultad de Antropología, UADY; 2014.

\section{FORMA DE CITAR}

Moreno Cabrera SA. Entre "saber y no saber tomar": representaciones y prácticas de varones y mujeres sobre el consumo de alcohol en Yucatán. Salud Colectiva. 2020;16:e2533. doi: 10.18294/sc.2020.2533.

Recibido: 1 sep 2019 | Versión final: 23 jun 2020 | Aprobado: 15 jul 2020 | Publicado en línea: 11 ago 2020

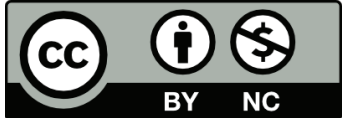

Esta obra está bajo una licencia de Creative Commons Reconocimiento-NoComercial 4.0 Internacional. Reconocimiento - Permite copiar, distribuir y comunicar públicamente la obra. A cambio, se debe reconocer y citar al autor original. No Comercial - Esta obra no puede ser utilizada con finalidades comerciales, a menos que se obtenga el permiso. 